\title{
双离子束浌射法生长 $\mathrm{MgO}$ 薄膜
}

\author{
李贻杰 熊光成 连贵君 李洁 甘子钊 \\ (北京大学物理系,北京 100871)
}

\section{关链词 $\mathrm{MgO}$ 薄膜、离子束涐射、外延生长}

氧化物薄膜近几年来受到了人们普遍的重视. $\mathrm{MgO} 、 \mathrm{SiO}_{2}$ 和 $\mathrm{ZrO}_{2}$ 等材料不仅可以用 作各种电子器件中的绝缘层, 还起到了隔离层的作用, 可有效地阻止多层膜之间因互扩散造 成的界面反应. 迄今为止, 实验已经证实许多材料都可作为很好的隔离层或多层膜中的绝缘 层, 包括 $\mathrm{SrTiO}_{3}{ }^{[1]} 、 \mathrm{Y}-\mathrm{ZrO}_{2}{ }^{[2]} 、 \mathrm{PrBa}_{2} \mathrm{Cu}_{3} \mathrm{O}_{7}{ }^{[3]} 、 \mathrm{Y}_{2} \mathrm{O}_{3}{ }^{[4]} 、 \mathrm{CeO}_{2}{ }^{[3]}$ 和 $\mathrm{MgO}^{[6]}$ 等. 这些材料在不 同的器件制备中具有不同的作用, 可供选择. $\mathrm{MgO}$ 是一种离子性很强的氧化物材料. 属 $\mathrm{NaCl}$ 结构, 溶点高达 $2800^{\circ} \mathrm{C}$, 介电常数为 10 , 自由能最低的低指数解理面为 $\{100\}$ 面, 晶格常数 为 $4.211 \AA$, 单晶 $\mathrm{MgO}$ 是生长 $\mathrm{YB}_{\mathrm{ai}_{2}} \mathrm{Cu}_{3} \mathrm{O}_{7-x}$ 超导薄膜较为理想的衬底, 也适合于外延生长 其它薄膜材料, 因此 $\mathrm{MgO}$ 薄膜是一种比较理想的隔离层材料. 用激光蒸发 ${ }^{[6]}$ 和分子束外延 ${ }^{[n}$ 方法制备 $\mathrm{MgO}$ 薄膜的工作已有报道, 我们首先采用双离子束浌射法在 (100) $\mathrm{SrTiO}_{3} 、(100)$ $\mathrm{Y}-\mathrm{ZrO}_{2}$ 以及 $(100)$ 和 (111) 取向的 $\mathrm{Si}$ 衬底上成功地生长出了 $\mathrm{MgO}$ 外延薄膜. 利用 $\mathrm{X}$ 射线 衍射 (XRD) 和反射式高能电子衍射 (RHEED) 对薄膜的取向与结构进行了研究.

\section{1 样品制备}

在薄膜淀积过程中, 主枪用于溅射 $\mathrm{MgO}$ 靶, 辅助枪用于祄底表面清洗及氧离子辅助沉 积. 离子枪栅网直径为 $25 \mathrm{~mm}$, 离子束能量 $150-1500 \mathrm{eV}$, 束流 $5-100 \mathrm{~mA}$, 践射离子束与靶之 间的夹角在 $0-90^{\circ}$ 范围内连续可调. 本底真空度为 $3 \times 10^{-4} \mathrm{~Pa}$, 衬底温度可在室温与 $900^{\circ} \mathrm{C}$ 之间任意调节. 当真空度超过 $3 \times 10^{-4} \mathrm{~Pa}$ 时, 将衬底加热到预定的温度, 然后在辅助枪中通入 $\mathrm{Ar}$ 气,工作气压为 $1 \times 10^{-2} \mathrm{~Pa}$ (靶室测量值), 用 $500 \mathrm{eV} 、 30 \mathrm{~mA}$ 的 $\mathrm{Ar}$ 离子束对祄底表面进 行清洗, 清洗时间针对不同的祄底材料有所不同, 一般在 $0.5-3 \mathrm{~min}$ 之间. 衬底清洗结束后 将 $\mathrm{Ar}$ 气通人主离子枪, $\mathrm{Ar}$ 分压为 $1 \times 10^{-2} \mathrm{~Pa}$, 主离子枪的溅射条件一般为: 离子束能量 $1000 \mathrm{eV}$, 束流 $50 \mathrm{~mA}$, 入射角 $45^{\circ} \mathrm{C}$. 溅射开始后, 将 $\mathrm{O}_{2}$ 气通入辅助离子枪, 氧分压为 $5 \times$ $10^{-3} \mathrm{~Pa}$. 氧离子辅助生长的条件为: 加速电压固定在 $150 \mathrm{~V}$, 束流在 $0-50 \mathrm{~mA}$ 之间变化. 通 过改变辅助枪的氧离子束流与衬底温度可在每一种衬底材料上获得最佳的淀积条件. 薄膜淀 积速率为 $20-30 \AA / \mathrm{min}$, 厚度在 $1000-1500 \AA$ 之间.

\section{2 结果与讨论}

实验中发现, 在 (100) $\mathrm{SrTiO}_{3}$ 和 $(100) \mathrm{Y}-\mathrm{ZrO}_{2}$ 衬底上生长 $\mathrm{MgO}$ 薄膜时, 能够直接成

1992-07-16 收稿, 1992-10-16 收修改稿. 
相的衬底温度范围比较宽,在 $500-800^{\circ} \mathrm{C}$ 的 温度范围内通过适当调节氧离子束流都能 获得 (100) 取向的 $\mathrm{MgO}$ 外延薄膜, 尤其是 在较低的祄底温度下仍能 实 现外延生长. Yang 和 Flynn ${ }^{[8]}$ 曾提出在离子性很强的化 合物中, 因为电中性解理面上原子的扩散运 动比其它面上要快得多, 所以即使在很低的 衬底温度(相当于材料溶点的百分之一) 下, 仍能实现外延生长. 我们在实验过程中发现 若衬底温度低于 $400^{\circ} \mathrm{C}$, 则 $\mathrm{MgO}$ 薄膜是非晶 态的. 在 $400-500^{\circ} \mathrm{C}$ 温度范围内, 虽然在 $X$-射线衍射谱中能够观察到 (200) 峰, 但峰 很弱, 并且半峰宽都在 $1^{\circ}$ 左右. 只有当祄底 温度大于 $500^{\circ} \mathrm{C}$ 时, $\mathrm{MgO}$ 薄膜的 (200)峰才明 显增强. 图 1 给出了辅助枪氧离子束流为 $30 \mathrm{~mA}$ 时, 在 (100) $\mathrm{SrTiO}_{3}$ 衬底上生长的 $\mathrm{MgO}$ 薄膜的 $\mathrm{X}$ 射线衍射谱. 从图中可看出, 在不同的衬底温度下只出现 (200) 峰, 说明 $\mathrm{MgO}$ 薄膜具有单一的 (100) 取向. 当衬底

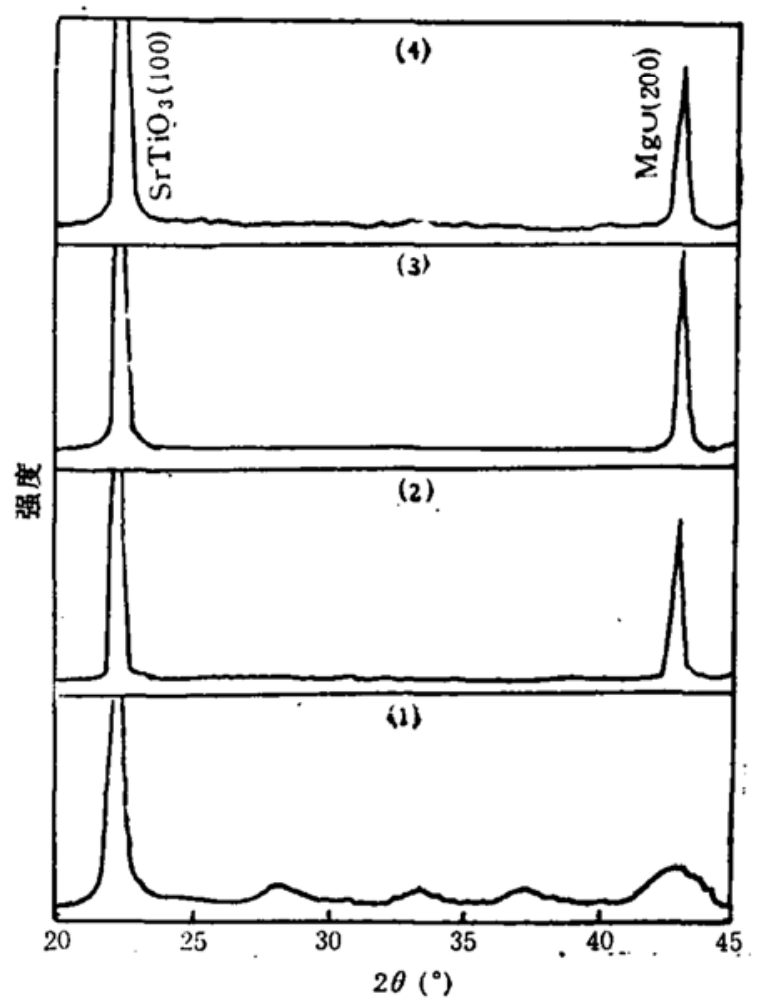

图 1 (100) $\mathrm{SrTiO}$, 祄底上 $\mathrm{MgO}$ 薄膜的 $\mathrm{X}$ 射线衍射图 村底温度分别为 (1) $500^{\circ} \mathrm{C},(2) 600^{\circ} \mathrm{C},(3) 650^{\circ} \mathrm{C},(4) 700^{\circ} \mathrm{C}$. 辅助枪氧离子束流为 $30 \mathrm{~mA}$ 温度为 $650^{\circ} \mathrm{C}$ 时, (200) 峰的半峰宽只有 $0.35^{\circ}$, 表明 $\mathrm{MgO}$ 薄膜具有较好的外延结构.

值得一提的是在 $\mathrm{Si}$ 祄底上生长 $\mathrm{MgO}$ 薄膜时, 适合外延生长的衬底温度范围比较窄, 只 有在 $600-650^{\circ} \mathrm{C}$ 的温度范围内, $\mathrm{MgO}$ 薄膜才具有较强的 (200) 衍射峰. 衬底温度过低或过 高,薄膜都表现为非晶态.此外, 在 $\mathrm{Si}$ 衬底上生长 $\mathrm{MgO} 、 \mathrm{ZrO}_{2}$ 等薄嗼时, $\mathrm{Si}$ 表面的氧化层

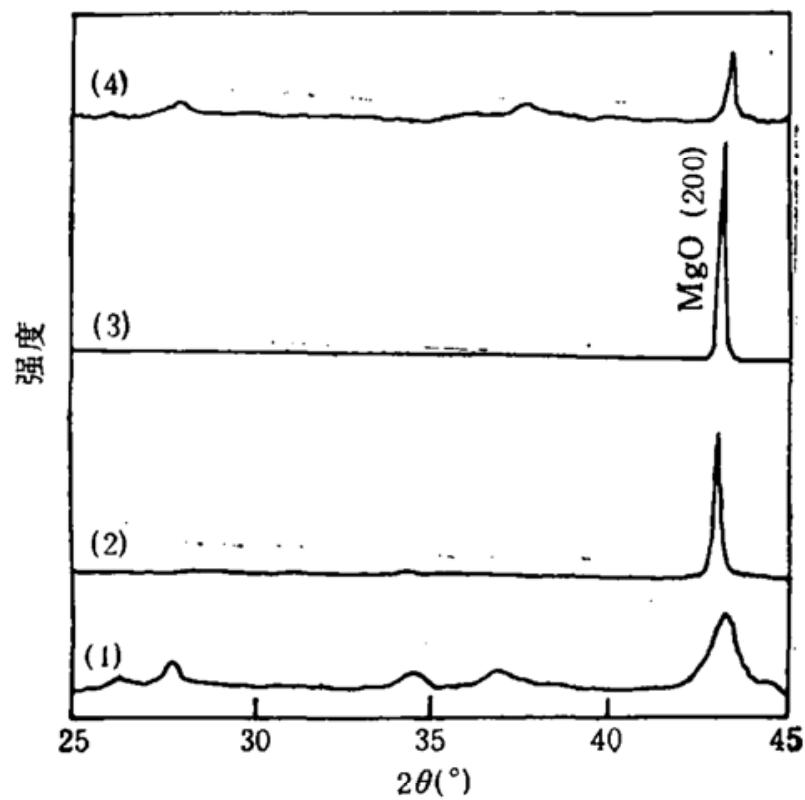

图 $2(100) \mathrm{Si}$ 祄底上 $\mathrm{MgO}$ 薄膜 $\mathrm{X}$ 射线衍射图随辅助氧离子束流的变化 村底温度为 $6000^{\circ} \mathrm{C}$, 氧束流分别为: (1) $10 \mathrm{~mA},(2) 20 \mathrm{~mA},(3) 30 \mathrm{~mA},(4) 40 \mathrm{~mA}$ 


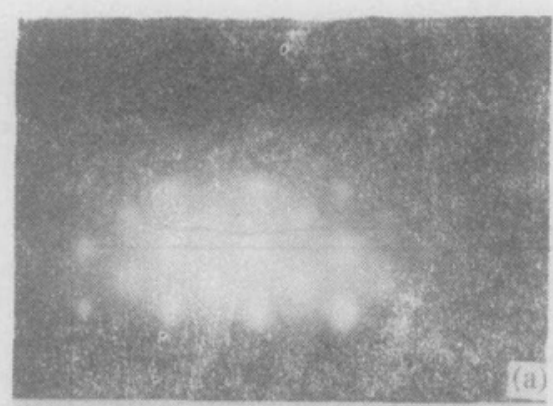

会严重影响薄膜的质量 ${ }^{[8,9]}$. 所以国外许多研究小组采取了 各种不同的方法来改进 $\mathrm{Si}$ 的表面 纯度, 如激光 清洗 ${ }^{[10]}$, 化 学保护[1]等. 我们采用离子束刻蚀的方法在淀积前对 $S i$ 袝 底表面进行清洗, 并且等賎射过程开始几分钟后, 再通氧进行 氧离子辅助生长, 这样可以避免 $\mathrm{Si}$ 表面氧化层对外延生长 的影响.

尽管金属 $\mathrm{Mg}$ 极容易氧化, 但在实验中发现, 氧离子束 流的大小对薄膜的外延生长仍起着决定性的作用. 如果在背 景压力 (氧分压小于 $10^{-4} \mathrm{~Pa}$ ) 下淀积, 则薄膜呈现出半透明状 的银灰色, 电阻值较小. 只有当氧离子束流超过 $10 \mathrm{~mA}$ 时, 薄膜才具有较强的 (200) 峰. 反之, 如果氧离子束流过大 $(>50 \mathrm{~mA})$, 薄膜同样是非晶态, 无法实现外延生长. 适合 于外延生长的最佳辅助䂇离子束流不仅与祄底材料的种类有 关, 而且还与祄底温度有关. 图 2 给出了祄底温度为 $600^{\circ} \mathrm{C}$ 时, 在 (100) $\mathrm{Si}$ 祄底上生长的一组 $\mathrm{MgO}$ 薄膜的 $\mathrm{X}$ 射线衍射 图. 从图中可看出, 当氧离子束流为 $30 \mathrm{~mA}$ 时, $\mathrm{MgO}$ 薄膜具 有很强的 (200) 峰、半峰宽只有 $0.4^{\circ}$, 显示出 $\mathrm{MgO}$ 薄膜具有 单一取向的外延结构. 虽然不同祄底材料对应的最佳生长工 艺有所不同, 但都表现出同样的规律. 造成这种差别的原因 主要是由于 $\mathrm{Mg}$ 和 $\mathrm{O}$ 这两种原子的粘附系数不同. 对某种 衬底材料, 只有在一定的氧离子束流下, 才能保证薄膜具有正 确的化学配比.

为了进一步分析薄膜的外延质量及表面状况, 还测量了
反射式高能电子衍射花样, 如图 3 所示. 从这些炤片可看出, 衬底材料分别为: (a) (100) $\mathrm{SrTiO}_{3}$,

(b) $(100) \mathrm{Y}_{-\mathrm{ZO}_{2}},(\mathrm{c})(100) \mathrm{Si}$

溥膜的反射式高能电子 衍射花样 不同祄底上生长的 $\mathrm{MgO}$ 薄膜的反射式高能电子衍射花样, 如图 3 所示. 从这些照片可看出, 在不同衬底材料上生长的 $\mathrm{MgO}$ 薄膜都显示出规则的衍射花样, 这说明样品至少在电子束斑 (几个微米)的范围内具有完整的晶格结构.

以上实验结果表明, 用双离子束戝射法可以在 $(100) \mathrm{SrTiO}_{3}(100) \mathrm{Y}-\mathrm{ZrO}_{2}$ 和 $\mathrm{Si}$ 等衬底 上获得 $[100]$ 取向的 $\mathrm{MgO}$ 外延薄膜. 通过氧离子辅助的办法不仅可以大大增强薄膜原子之 间的结合力,还可降低祄底温度. $\mathrm{X}$ 射线衍射和反射式高能电子衍射测量证明 $\mathrm{MgO}$ 薄膜舆 有 [100] 取向的外延结构.

\section{参考文献}

[ 1 ] Kingston, J. J., Wellstool, F. C., Lerch, P. et al., Appl. Phys. Lett., 1990, 56(2): 189-191.

[ 2 ] Fork, D. K., Fenner, D. B., Barton, R. W. et al., Apppl. Phys. Lezz., 1990, 57(11): 1161-1163.

[ 3 ] Rogers, C. T., Inam, A., Hegde, M. S. ct al., Appl. Phys. Letz., 1989, 55(19): $2032-2034$.

[4] Berezin, A. B., Yuan, C. W., de Lozanne, A. L., Appl. Phys. Letz, 1990, 57(1): 90—92.

[ 5 ] Inoue, T., Yamamoto, Y., Koyama, S. ct al., Appl. Phys. Lett., 1990, 56(14): 1332-1333.

[6] Garrison, S. M., Newman, N., Cole, B. F. ct al., Appl Phys. Lett., 1991, 58(19): 2168-2170.

[ 7 ] Yadavalli, S., Yang, M. H., Flynn, C. P., Phys. Rev. B, 1990, 41(11): 7961-7963.

[ 8 ] Yang, M. H., Flynn, C. P., Phys. Rev. Lett, 1989, 62(21): 2476-2479.

[ 9 ] Obara, H., Kosada, S., Kimura, Y., Appl Phys. Lett., 1991, 58(3): 298-300.

[10] Vispute, R. D., Kanetkar, S. M., Ogale, S. B. et al, Physica C, 1992, 199(1812): 59-64.

111] Fenner, D. B., Biegelsen, D. K., Bringans, R. D., J. Appl. Phys, 1989, 66(1): 419-424. 